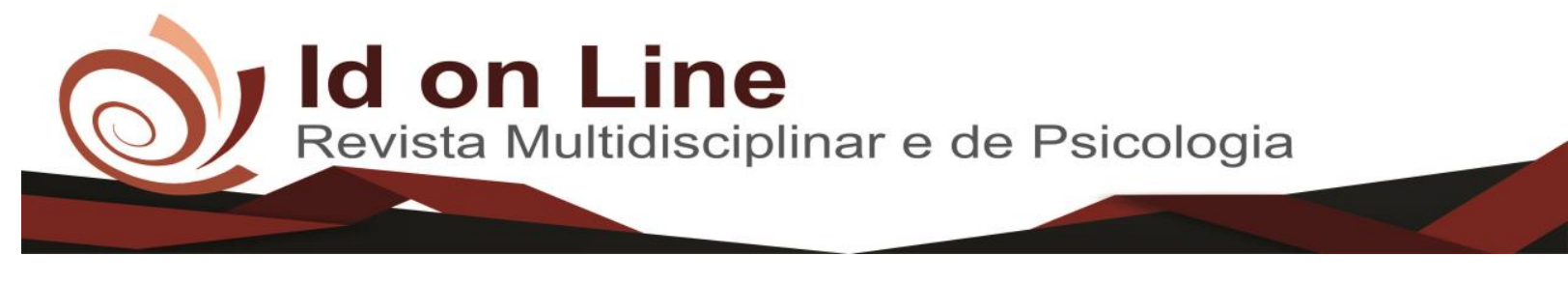

Artigo de Revisão

\title{
O Papel do Líder no Serviço Público
}

Wilton Alves de Oliveira ${ }^{1}$; Anna Ariane Araújo de Lavor ${ }^{2}$; Anna Rosina Araujo Lavor ${ }^{3}$; Francisco Francinildo Oliveira Lima ${ }^{4}$; Martilla Sousa Silva ${ }^{5}$; Sávio Nogueira Almino ${ }^{6}$; Thamires de Oliveira Mota Menezes Gomes ${ }^{7}$

Resumo: Este trabalho tem por objetivo caracterizar o papel do líder no serviço publico, no qual são abordados os estilos de liderança desde a Administração Científica até os dias atuais. A partir de tal abordagem são examinados os conceitos e a importância da liderança segundo diversos autores. Destaca ainda a relação entre líder e liderados, os tipos de líderes, as características pessoais, traços de personalidade, habilidades pessoais e novas teorias sobre o líder que o mercado hoje está exigindo. A liderança hoje é uma ferramenta de suma importância no campo da administração, pois é através dela que o líder procura juntamente com os seus liderados atingir os objetivos traçados em seu plano de ação. Este artigo foi embasado em diversas consultas bibliográficas de diversos autores que contribuíram para a contextualização e realização do mesmo. A metodologia aplicada para realização deste foi a utilização de pesquisas bibliográficas. Ao final pode-se perceber a necessidade da liderança no mundo de hoje, pois as organizações a cada dia que passa estão sempre apostando nas pessoas que constituem a empresa e com isso mudam e quebram os paradigmas, que antes viam o homem como peça que conduzia uma máquina, passando agora a ser considerado como parte fundamental para consecução de objetivos.

Palavras-chave: Liderança. Administração. Serviço Público.

\section{Leadership Role in Public Sector}

Abstract: This paper aims to characterize the role of the leader in the public service, in which leadership styles are addressed from the Scientific Administration to the present day. Based on this approach, the concepts and importance of leadership according to several authors are examined. It also highlights the relationship between leader and lead, types of leaders, personal characteristics, personality traits, personal skills and new theories about the leader the market today is demanding. Leadership today is a very important tool in the field of administration, because it is through it that the leader seeks together with his or her leaders to achieve the goals outlined in their action plan. This article was based on several bibliographical consultations of several authors that contributed to

\footnotetext{
${ }^{1}$ Graduado em Administração.

${ }^{2}$ Graduação em Direito pela Universidade Regional do Cariri, MBA (especialização) em Direito Civil e Processual Civil pela ESAB, mestrado em Ambiente e Desenvolvimento pela UNIVATES. Doutoranda em Ambiente e Desenvolvimento pela UNIVATES. E-mail: annaariane@hotmail.com

${ }^{3}$ Graduação em Letras - Português/Inglês, pela Universidade Estadual do Ceará, Pós-Graduação Lato Sensu em Administração e Marketing pela Escola Superior Aberta do Brasil e MBA Profissional em Gestão de Recursos Humanos, também pela Escola Superior Aberta do Brasil. Técnico-Administrativo em Educação do Instituto Federal de Educação, Ciência e Tecnologia do Ceará - Campus Iguatu;

${ }^{4}$ Graduado em Letras pela Universidade Estadual do Ceará, com Especialização em Literatura Brasileira pela Universidade Regioal do Cariri- URCA. Graduado em Direito pela Universidade Regional do Cariri. com Especialização em Direito Penal e Criminologia pela Universidade Regional do Cariri- URCA. Pós graduando em Direito Imobiliário pela Faculdade Vale do Salgado -FVS;

${ }^{5}$ Graduação em Administração pela Faculdade Vale do Salgado, Pós-Graduação Latu Sensu em Administração, Finanças e Marketing pela Faculdade Leão Sampaio (2012). Técnico Administrativo em Educação do Instituto Federal de Educação, Ciência e Tecnologia do Ceará campus Iguatu;

${ }^{6}$ Graduação em Direito pela Universidade Regional do Cariri. Técnico em Agropecuária do Instituto Federal do Ceará , Brasil;

${ }^{7}$ Graduação no Curso de Bacharelado em Direito pela Universidade Regional do Cariri - URCA. Especialização em Direito Previdenciário e Trabalhista pela Universidade Regional do Cariri - URCA. Servidora Pública do Instituto Federal de Educação, Ciência e Tecnologia do Ceará - campus Iguatu.
} 
the contextualization and accomplishment of the same. The methodology used for this was the use of bibliographical researches. In the end, one can see the need for leadership in today's world, as organizations with every passing day are always betting on the people who make up the company and with that they change and break the paradigms, which used to see man as the leading piece a machine, now being considered as a fundamental part to achieve objectives.

Keywords: Leadership. Administration. Public service.

\section{Introdução}

A liderança pode ter significados diferentes para alguns autores, porém é um processo que envolve a influência de pessoas com vista à realização de atingir objetivos comuns. Assim pode se afirmar que liderança é uma qualidade que faz com que um indivíduo desperte em outro o desejo de segui-lo. Atualmente, a liderança no serviço publico é de grande importância, pois é através dela que os líderes conseguem desenvolver habilidades com intuito de conduzir as pessoas para consecução de objetivos traçados.

O artigo trabalho tem como objetivo identificar o papel do líder no serviço público, o estilo de liderança dominante, suas características e habilidades pessoais, tipo de comunicação, conceitos e importância sobre liderança, os traços de personalidade destes líderes e as novas teorias de liderança atuais. Assim, a liderança deve contribuir para a melhoria das interações humanas em qualquer ambiente de trabalho, onde o líder procura através de suas habilidades mecanismos de influência em relação aos seus liderados, levando os colaboradores a trabalharem entusiasticamente para obtenção dos planos traçados. Portanto, ainda tem como objetivos: mostrar que a liderança é uma ferramenta de gestão totalmente voltada para garantir e assegurar o bem-estar das pessoas (servidores e colaboradores), onde através de suas características e habilidades contribuem para um ambiente saudável e agradável.

A liderança é uma função, papel ou tarefa que qualquer pessoa desempenha quando é responsável por um grupo, independente de possuir qualidades ou não. Diante o exposto, surge o seguinte questionamento em referência ao assunto: Qual o papel do líder no serviço publico?

Em resposta, pode-se dizer que o papel do líder é aquele em que os diretores/coordenadores e chefes de departamento, gestores, conseguem através de suas habilidades de liderança alocar a pessoa certa no local certo com base na analise de seu perfil, sabem delegar, escutam seus subordinados, possuem um ótimo canal de comunicação, tomam 
decisões de forma clara e coerente, respeitam e valorizam as pessoas com quem trabalham e acima de tudo são honestos e íntegros.

Diante deste contexto surgiu o interesse de estudar o papel do líder no serviço publico, os estilos de lideranças aplicados nestes órgãos, a forma de comunicação entre eles e outras características existentes em um líder, para enfim poder confrontar com que diz os autores.

Este artigo foi divido em introdução, desenvolvimento e considerações finais. A pesquisa originou-se de consultas bibliográficas, na qual se destaca alguns autores consultados para realização do mesmo: Azevedo (2009), Buono e Bowditch (2006), Maximiano(2000), Robbins(2002), e dentre outros. O desenvolvimento deste trabalho aborda ainda o Papel do Líder no Serviço Publico, os estilos de liderança, canal de comunicação, habilidades e outras características; os tipos de líder com base na relação dos liderados; as características e habilidades pessoais do líder, que podem ser identificadas sejam através de sua personalidade,comportamento; traços de personalidades, que são características determinantes que um líder possui; motivação dos líderes, a forma como eles estão motivados para poderem assim motivarem seus liderados; tipos de liderados, onde neste pode se deparar com pessoas fáceis de se relacionarem ou não; e novas teorias sobre líder que tende a mostrar o novo perfil do líder exigido no mercado de hoje.

Por último, nas considerações finais, onde apresentamos os resultados que demonstram a importância de um líder no serviço público, onde através de suas habilidades fazem com que os colaboradores sintam prazer em segui-lo e com isso consigam atingir as metas traçadas, transformando o homem como parte fundamental para a consecução de objetivos e não apenas mera peça do sistema.

\section{O Papel do Líder}

O presente artigo tem por objetivo mostrar o papel do líder, suas características pessoais, habilidades desenvolvidas, tipos de liderados, relação existente entre líder e liderados e novas teorias sobre o líder. Para Maximiano (2000, p.394), “Os líderes podem ser descritos como figura humana que permite definir a liderança como função, papel ou tarefa, que qualquer pessoa precisa desempenhar, quando é responsável pelo desempenho de um grupo. " Portanto, pode-se dizer que um líder é aquele que através de sua posição, detendo de suas habilidades, 
conduz seu grupo a desenvolverem suas atividades com o objetivo de atingir aos anseios por ele almejado. Para isso, o líder precisa ser: íntegro, inteligente, comunicativo, honesto, bondoso, humilde e acima de tudo saber valorizar as pessoas, sendo uma das principais características, o carisma.

Segundo Maximiano (2000, p. 398), “carisma é a qualidade pessoal que, segundo Weber, desperta a devoção dos seguidores. Carisma significa dom divino. " Baseados no que diz o autor, um líder para ser bem-sucedido numa organização a fim de conquistar seus liderados é preciso acima de tudo ter humildade e carisma além de outras qualidades e assim com isso, conquistará seus aliados no intuito de conduzi-los a atingir as metas estabelecidas. Isso mostra que o líder é aquele que conquista seus seguidores para que juntos possam atingir os objetivos traçados pela organização. Então podemos dizer que todo órgão é constituído por pessoas, mas o que as tornam diferente das demais é a forma de como os líderes influenciam seus liderados para poderem agir em seu favor e com isso atingir aos anseios traçados.

\section{Tipos de líder com base na relação dos liderados}

O líder é aquele que influência os outros a fazer uma determinada tarefa no objetivo de atingir as metas da organização. Portanto os líderes precisam conquistar seus liderados para chegar a este objetivo. Para Maximiano (2000, p.391): “os líderes que arrastam multidões, capazes de conceber uma grande idéia, de juntar uma multidão suficientemente grande para concretizá-la e de pressionar a multidão para que, de fato, a concretize. "Estes são os líderes que detendo de seu poder, faz com os seus seguidores realizem qualquer tarefa a que lhes forem atribuídas. Este líder é simplesmente aquele que usa o poder como forma conduzir os liderados para poder atingir aos objetivos de sua organização.

Maximiano (2000, p.391) deixa claro que: "Os líderes que representam as multidões limitam-se a exprimir apenas a opinião coletiva, de forma já conhecida e definida. " Este líder que representam as multidões é aquele que exprimem apenas os interesses comum do grupo. Então, pode-se dizer que na liderança os líderes são pessoas que conquistam, interpretam e arrastam multidões por onde passam, eles são capazes de conduzir seus liderados a desenvolverem suas tarefas no objetivo de atingir as metas traçadas por eles. 


\section{Características Pessoais do líder}

As características pessoais do líder podem ser identificadas através de diversas formas como: habilidades, personalidade, comportamento e outras pessoais que possa aparecer quando surge algo inesperado para ser solucionado. No entanto o líder pode apresentar diversas características, mas elas não são comuns a todos.

Segundo Maximiano (2000, p.400), “O estudo do líder como pessoa tenta entender quais comportamentos, traços de personalidade, habilidades, atitudes e outras características pessoais são determinantes do desempenho eficaz do líder. "São através destas características que o líder analisa as suas habilidades, atitudes e outras que possa existir para que em cima disso possa mostrar que pode desempenhar qualquer função que lhe seja atribuída sendo ele capaz de liderar as pessoas que lhes rodeiam.

Segundo Azevedo (2009), “ Líderes surgem, crescem, aparecem, não se autointitulam, líderes são reconhecidos e seguidos, colocados no topo, o verdadeiro líder não busca a liderança, ele a executa de fato, com instinto e também com habilidades e competências, que podem ser adquiridas, compreendidas, mas não pré-concebidas! ”. Isso mostra que os líderes não nascem prontos e sim desenvolvem habilidades que os tornam líderes. Portanto pode-se dizer que líderes são pessoas comuns, mas com habilidades diferenciadas que os tornam aptos a serem condutores de pessoas para consecução de objetivos, são titulados de verdadeiros, íntegros, sinceros, calmos, otimistas e outras qualidades que surgem. Então líder não possui nome de liderança, nem nome de qualidades, mas possuem caráter e habilidades que são reconhecidas e compreendidas.

Azevedo (2009) diz ainda que "Liderar é muito mais do que simplesmente dar ordens, apontar o dedo, mandar fazer. Um líder puxa a fila, dá o exemplo, e pode ser servidor sim, mas precisa inspirar confiança, identificar habilidades e aprender a diferença entre os desejos e as necessidades de seus liderados. "Conforme cita o autor, o líder é uma pessoa como qualquer outra, só que com habilidades diferentes e com capacidade de conduzir pessoas a consecução de atingir aos objetivos traçados. Ele precisa sempre inspirar confiança e nunca misturar o que é desejo e necessidades dos seus liderados. Portanto, chefiar é fácil e existem muitos chefes por aí. Administradores precisam de talento, mesmo assim, não é difícil encontrá-los. Pois, para chefiar, basta ter poder. Para administrar é preciso o acompanhamento e o conhecimento. Para liderar é vital saber antes de tudo, aprender a servir e se doar. 
Azevedo (2009) ressalta ainda que: "Um líder nato costuma ter sobrenomes como: Iniciativa, perseverança, objetividade, paciência, flexibilidade, sensatez, justiça, positivismo e compromisso. "Segundo o autor, estes sobrenomes que um líder costuma a ter são características que desenvolvem quando exercem uma posição de liderança. Para isso cada líder deve ter iniciativa em qualquer situação, ser sempre objetivo, agir rápido, paciente para conduzir, por exemplo, uma tarefa difícil, flexível nas tomadas de decisões, justo para com seus colaboradores e compromissado com a empresa e seus liderados.

Segundo Prazeres (2005, p. 222), "liderança não é uma condição passiva, mas produto de participação, envolvimento, comunicação, cooperação, negociação, iniciativa e responsabilidade. " Então, liderança nada mais é que habilidades que pessoas desencadeiam em seu dia a dia, sendo-as expressas pelo líder quando tratam seus colaboradores ou demais pessoas. Estas habilidades são colocadas em pratica quando as circunstâncias exigem e através delas e do espírito de companheirismo que os lideres conquistam seus subordinados.

\section{Traços de personalidade}

Existe na liderança formas de identificar as qualidades de uma pessoa, seus traços de personalidade, e são através destas qualidades que se analisa se a pessoa é apta ou não a se tornar líder. Hoje, no Serviço Público procura-se pessoas que possuem características de líderes, capazes de conduzir outras para com isso atingir os objetivos do órgão.

Uma das formas de estudar a liderança consiste em focalizar a personalidade dos líderes. Esse tipo de estudo baseia-se em biografias e em incidentes críticos (situação em que alguém desempenhou papel de liderança). (MAXIMIANO, 2000, p.400)

Portanto, o traço de personalidade é uma das formas que as organizações utilizam para identificar se uma pessoa é apta a tornasse líder ou não, seja através de sua biografia ou mesmo através de registros anteriores em que desempenhou papel e/ou função de líder.

O autor ainda diz que:

Sabe-se que os líderes têm determinados traços de personalidade. No entanto, as pessoas que tem os mesmos traços não são nem se tornam, necessariamente, líderes. Além disso, até hoje não se conseguiu identificar um conjunto de traços de personalidade comum a todos os líderes. (MAXIMIANO, 2000, p.400) 
De acordo com o autor, nem toda pessoa que possui as mesmas aptidões se tornam líderes, algumas possuem traços que as levam a tornar-se, sendo estas capazes de conduzir as demais do grupo a desempenharem suas atividades, através de seu meio de persuasão e outras que podem desenvolver, mas não possui capacidade de conduzi-las a um determinado objetivo.

Robbins também deixa claro que:

Seis traços costumam diferenciar os líderes dos liderados, são ambição e energia, desejo de liderar, honestidade e integridade, autoconfiança, inteligência e conhecimentos relevantes para o trabalho. Além disso, pesquisas recentes mostram que fortes evidências de que as pessoas com elevado grau de auto-monitoramento isto é, altamente flexíveis para ajustar seu comportamento a diferentes situações - tem probabilidade muito maior de surgir como líderes nos grupos. (ROBBINS, 2002, p.304)

Entende-se, portanto, que as pessoas que possuem estas características têm maior probabilidade de torna-se líder, mas isso não significa que será. Muitas pessoas podem apresentar estes traços, o que difere realmente o líder do liderado, mas o verdadeiro líder é aquele que possui: entusiasmo, integridade, segurança, disciplina e perseverança e acima de tudo desejo de liderar. Assim podemos afirmar que o verdadeiro líder é aquele que esta sempre buscando cada vez mais aprimorar suas habilidades e através de sua personalidade procura ser mais perspicaz, assertivos, persuasivos, empáticos e inovadores, suficientes para assumirem riscos.

Outros autores Buono e Bowditch (2006) dizem ainda que:

\begin{abstract}
As antigas abordagens da liderança enfocavam características e atributos pessoais físicos mentais e culturais - que pareciam diferençar entre líderes e seguidores. Essa linha de pesquisa sobre liderança é muitas vezes denominada teoria da "Pessoa Grandiosa", uma vez que se suponha que os líderes eram bastante diferentes das pessoas médias em termos de algumas características de personalidade e de características físicas. (BUONO; BOWDITCH, 2006, p.147)
\end{abstract}

Conforme os autores, estas características e atributos diferenciam os líderes dos liderados, pois nem toda pessoa apresenta habilidades para torna-se líder. Os líderes apresentam habilidades como delegar tarefas, iniciativa, integridade, entusiasmos, bom humor, sabem elogiar na hora certa, estimulam e motivam seus colaboradores na consecução de suas tarefas e acima de tudo são humildes.

Buono e Bowditch (2006), ressaltam que: de acordo com as revisões sobre as pesquisas de liderança, existe, por exemplo, cinco características pessoais que precisam estar relacionadas, presentes numa liderança efetiva: inteligência, domínio, autoconfiança, altos 
níveis de energia e atividade, e conhecimento pertinente à tarefa. Vale destacar que um bom líder não basta ter somente estas características para alcançar o sucesso, ele precisa de outras, pois pode se deparar com situações em que terá de mostrar diferentes habilidades para solucioná-las.

\section{Habilidades pessoais}

A liderança é a atividade de influenciar pessoas a desempenharem suas tarefas para consecução de um objetivo. Portanto, para se ter uma boa liderança, o líder precisa desenvolver habilidades que através dela conquistarão seus liderados e levarão a empresa ao sucesso, isso tudo por meio de uma liderança segura baseada em habilidades.

Outra forma de pesquisa focaliza a liderança como habilidade que pode ser desenvolvida. Um dos autores mais conhecidos dessa linha é Mintzberg, que enxerga a liderança não como habilidade singular, mas como complexo de tarefa e habilidades. (MAXIMIANO, 2000, p.401)

Sabemos que não nascemos com habilidade e sim desenvolvemos. E são estas habilidades que fazem a diferença na forma de liderar. Então se pode dizer que qualquer pessoa tem possibilidade de tornar-se líder, mas para isso é preciso desenvolver certas habilidades que os tornará apto a exercer o papel de liderança. A pessoa para se tornar líder é preciso ser autentico, possui desejo de liderar, valorizar e reconhecer pessoas, ser compreensivo, estimular novas idéias, admitir erros, ser criativo, ousar sem medo de errar e mas outras habilidades pessoais que possa surgir.

\footnotetext{
A habilidade de comunicação oferece um dos melhores argumentos para demonstrar que certas características dos líderes podem ser e são de fato desenvolvidas. A comunicação é o alicerce da liderança, uma vez que o requisito básico para um líder é a capacidade de transmitir sua mensagem de modo a persuadir, inspirar ou motivar seus seguidores. (MAXIMIANO, 2000, p.401)
}

Comunicar é transmitir conhecimento, passar informação, emitir opinião, um líder para ser bem-sucedido em uma organização, precisa saber comunicar-se, transmitir a sua mensagem de modo que seus seguidores atendam as ordens ditadas. No entanto isso mostra que o líder precisa comunicar-se sempre com seus liderados, pois esta ferramenta é indispensável para atingir as metas traçadas. Um bom relacionamento parte de uma boa comunicação. 
O autor ainda deixa claro que:

Habilidades podem ser desenvolvidas a partir de aptidões. Portanto, a liderança não é um atributo inato, mas qualidade que qualquer pessoa pode desenvolver, desde que tenha motivação. Desse modo, o estudo das habilidades torna a liderança uma competência acessível por meio de educação, treinamento e experiência. (MAXIMIANO, 2000, p.402)

Deduz-se então que a liderança é uma habilidade que pode ser desenvolvida por qualquer pessoa, desde que esta encontre ambiente propício para desenvolvê-la. Assim, podese dizer que estas habilidades é que os tornará líder ou não. Um líder a partir de suas aptidões pode desencandear certas habilidades que leva a liderar um grupo de pessoas a consecução de um objetivo. Para isso é preciso está inserido em um ambiente agradável e motivado no qual juntamente com seus seguidores conseguirão desenvolver as tarefas com êxito.

\section{Novas Teorias sobre o líder}

O novo perfil dos líderes hoje exigido no mercado são aqueles: carismático, que valorizam as pessoas, motiva seus colaboradores, sabem ouvir e dão feedback. No entanto nem todo órgão usa esta ferramenta, pois nela existe o constrangimento de repreender um colaborador ou valorizar demais outro.

Segundo Faccioli (2008), a liderança carismática surgiu da necessidade de comparação ao modelo focado no paradigma democracia-autocracia. Um estilo de liderança muito próximo da motivação e dos estudos comportamentais do ser humano, a forma de como eles se comportam em determinadas situações, sendo motivados ou não e em comparação aos líderes autocrático que toma decisões sem a devida participação dos liderados, onde ele domina, decide e deixa as pessoas de seu grupo inseguras, porque começam a desenvolver um sentimento de inutilidade, porque nenhuma idéia sua é boa o suficiente para ser aproveitada e o líder democrático primeiro escuta seus liderados e em cima disso toma decisões.

Daí surge o líder carismático, que é aquele que promove mudanças que tem como principal foco renovar paradigmas, despertar sonhos e conduzir seus seguidores a transcender interesses pessoais na realização de determinada ação em prol do sucesso do grupo.

Segundo Kohlrieser (2007), as organizações hoje procuram líderes que detém de qualidades para conduzir negócios e para isso precisam estar preparados para entender e 
influenciar os liderados que os seguirão. Portanto, um líder precisa ter habilidade para controlar suas emoções, inspirar e criar um ambiente saudável e de cooperação e confiança, bem como ajudar aqueles que são injustiçados e humilhados pelos demais da equipe a se relacionarem melhor em grupo. Precisam ainda estar preparados para tensões, conflitos e problemas que precisaram resolver e, além disso, precisarão de um senso de proteção para ajudar a comunicar e entender por que a mudança é necessária.

Existem diferentes estilos de liderança, que exercem um impacto significativo, direto e exclusivo em um ambiente de trabalho, para isso, um líder precisa de utilizar-se destas ferramentas pra conseguir conduzir sua equipe ao sucesso da organização.

O estilo visionário concentra-se em conduzir as pessoas em direção aos sonhos compartilhados e à mobilização dos membros da organização em direção a visão. Este estilo é mais eficaz quando se faz necessária uma mudança organizacional que exija uma nova visão ou uma direção clara, e enfatiza a autoconfiança, a empatia e o fato de ser um catalisador da mudança. (BUONO; BOWDITCH, 2006, p.153)

Para isso o líder precisa possuir uma visão holística, para poder entender e compreender as necessidades dos clientes, tendo em vista competições entre as organizações. Um líder visionário é aquele focado no futuro, onde detém de uma visão macro e micro do negócio e do mercado. É aquele que possui a capacidade de realizar adaptações, provocar mudanças e colocar em prática suas idéias, realizar um verdadeiro trabalho em equipe.

O autor destaca ainda que:

O estilo Coaching conecta o que as pessoas querem com as metas da organização e desenvolve das pessoas. Dá-se ênfase à ajuda aos membros da organização para que melhorem seu desempenho construindo capacitações de longo prazo, e recorre à empatia, à consciência de si e à disposição do líder em ajudar os outros. (BUONO; BOWDITCH, 2006, p.153)

O líder coaching é o mais efetivo no estilo de liderança, nele temos um modelo de liderança voltado para as exigências do mercado. É aquele que cria condições para que seus liderados desenvolvam sua iniciativa e criatividade. Com isso os líderes ajudam os liderados a desenvolverem seu potencial, através da empatia. Vale destacar que o líder coaching é aquele que se preocupa com o desenvolvimento de seus liderados tanto nas organizações como fora delas, eles procuram sentir o que eles sentem, de querer o que eles querem e de aprender do modo que eles aprendem, para em cima disso aplicar um estilo de liderança que leve a empresa ao sucesso. 
O estilo afiliativo procura criar harmonia ligando as pessoas umas às outras e criando laços e apegos emocionais fortes. Enfoca-se o saneamento de diferenças dentro de uma equipe ou a ajuda às pessoas para que saibam lidar com situações estressantes. Este estilo provém da empatia do líder e de suas habilidades de comunicação e de construção de relações. (BUONO; BOWDITCH, 2006, p.153)

Este modelo de liderança estabelece relações pessoais entre líder e liderados e de liderados e liderados. O líder afiliativo é aquele que cria harmonia para acabar conflitos entre as pessoas e motivar em momentos de estresses, ele sempre procura aproximar a equipe.

O estilo democrático valoriza a colaboração das pessoas e a conquista do comprometimento e do consenso por meio da participação. Esse conjunto de comportamentos é muito útil para se criar compromisso e construir consenso, gerando recursos a partir de funcionários valorizados, e provém das habilidades de colaboração e de comunicação do líder. (BUONO; BOWDITCH, 2006, p.153)

O líder democrático é aquele que orienta o grupo a executar suas atividades e juntamente com seus colaboradores traçam as metas a serem seguidas. O líder escuta seus liderados e em cima disso toma as decisões na organização.

\section{Considerações Finais}

Toda organização hoje precisa de uma pessoa (líder) que saiba conduzir outras para consecução de suas atividades e obtenção de objetivos. No entanto a liderança tem se tornado no mundo atual, uma ferramenta de suma importância, pois é através dela que os líderes desenvolvem suas habilidades e identificam os meios e caminhos que precisam tomar para conseguirem atingir os objetivos traçados.

Em consequência, abordamos neste trabalho, através de consultas bibliográficas, o papel do líder no serviço público, que após várias mudanças e com surgimentos de novos conceitos passaram a ver o homem como parte fundamental destes órgãos. Com relação aos objetivos proposto pelo trabalho, podemos constatar que atualmente estas repartições possuem em seu ambiente de trabalho um líder que sabe comunicar, tomar decisões eficazes, respeitam e valorizam as pessoas, têm iniciativa, são compromissados, sabem delegar tarefas e possuem uma visão macroeconômica de mercado.

A pesquisa bibliográfica apresentada mostrou que em todo ambiente de trabalho é necessária a figura de um líder, o qual estimula os liderados a enfrentarem novos desafios, a 
cumprir metas, preocupa-se com o ambiente de trabalho em que estão inseridos e envolvidos e com a qualidade de vida dos mesmos. Ainda com base nas consultas bibliográficas, pode-se dizer que o estilo de liderança aplicado na maioria dos órgãos públicos é do tipo democrático, onde os liderados têm a participação nas tomadas de decisões, o que deixa claro, expressão dos colaboradores, ficando a cargo do líder a decisão final.

Salienta-se ainda que os líderes sabem respeitar as diferenças e estilos existentes de cada liderado, são adaptáveis a mudanças e aberto ao novo, possuem capacidade extraordinária de inverter certos acontecimentos antes de se tornarem problemas e detêm de qualidades que através delas conseguem influenciar, motivar e estimular as pessoas nos projetos e ações da organização, objetivando assim atingir as metas traçadas e acima de tudo são comunicativos para que possam através desta ferramenta entender e compreender seus liderados, sempre procurando estimulá-los para o sucesso, tanto pessoal, como profissional.

Neste sentido, podemos dizer que através dos objetivos traçados neste trabalho, pôdese através das hipóteses que foram validadas, responder ao problema apresentado. Portanto, surge-se o motivo pelo qual a importância de um líder no serviço público, onde através de suas habilidades fazem com que os colaboradores sintam prazer em segui-lo e com isso consigam atingir as metas traçadas.

Assim pode-se destacar a necessidade da liderança no mundo de hoje, pois as organizações a cada dia que passa estão sempre apostando nas pessoas que constituem a empresa e com isso mudam e quebram os paradigmas, que antes viam o homem como peça que conduzia uma máquina, passando agora a ser considerado como parte fundamental para consecução de objetivos.

\section{Referências}

ANDRADE, Maria Margarida de. Introdução à metodologia do trabalho científico: elaboração de trabalhos na graduação. 8. ed. São Paulo: Atlas, 2007.

AZEVEDO, Fabio. Líder! Eu?, 2009. Disponível em: <http://www.administradores.com.br /artigos/1_i_d_e_r_e_u/28801>. Acesso em 01 de mar. de 2018.

BOWDITCH, James L.; BUONO, Anthony F. Fundamentos de comportamento organizacional, 6. ed.. Edt. LTC, Rio de Janeiro, 2006. 
FACCIOLI, Cintia. Teorias de liderança, 2008. Disponível em: <http://www.administradores.com.br/artigos/teorias_de_lideranca/22664>.

Acesso em 04 de mar. de 2018.

KOHLRIESER, George. O perfil do líder moderno. Revista Você s/a, jul. 2007.

MAXIMIANO, Antonio César Amaru. Teoria geral da administração: da escola cientifica à competitividade na economia globalizada. 2. ed. São Paulo: Atlas, 2000.

. Introdução à administração. 5. ed. São Paulo: Atlas, 2000.

PRAZERES, Helio Tadeu Cury. "Como administrar pequenas empresas". Minas Gerais, 2005.

ROBBINS, Stephen Paul. Comportamento organizacional. 9. ed. São Paulo: Prentice Hall, 2002.

\section{Como citar este artigo (Formato ABNT):}

OLIVEIRA, Wilton A. de; LAVOR, Anna Ariane A. de; LAVOR, Anna Rosina A.; LIMA, Francisco F. O.; SILVA, Martilla S.; ALMINO, Sávio N. ; GOMES, Thamires de O. M. M. O Papel do Líder no Serviço Público. Id on Line Rev.Mult. Psic., 2018, vol.12, n.40, p.490-502. ISSN: 1981-1179.

Recebido: $17 / 04 / 2018$

Aceito 19/04/2018 